In Memoriam

\title{
Prof. Dr. Rui Raul Dahas de Carvalho
}

\author{
José Carlos Esteves Veiga ${ }^{1}$ Raul Dahas de Carvalho Neto ${ }^{2}$ Antero Costa Filho ${ }^{3}$ \\ 1 Departamento de Cirurgia, Irmandade da Santa Casa de \\ Misericórdia, São Paulo, SP, Brasil \\ 2 Neurocirurgião \\ 3 Professor Assistente da Faculdade de Ciências Médicas da Santa Casa \\ de Misericórdia, São Paulo, SP, Brasil
}

Arq Bras Neurocir 2015;34:95-96.

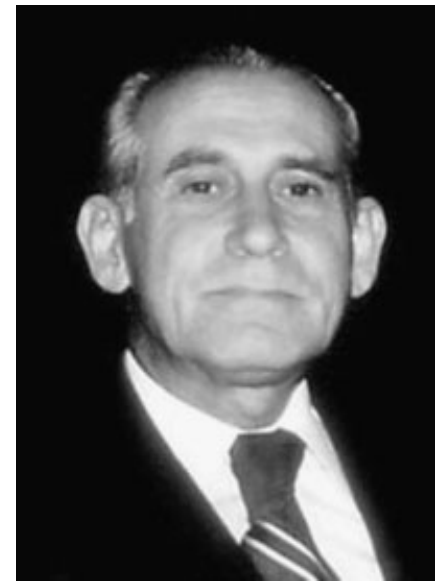

Fig. 1 Prof. Dr. Rui Raul Dahas de Carvalho, 1932-2014.

O Prof. Dr. Rui Raul Dahas de Carvalho (-Fig. 1) nasceu em Barretos, cidade do interior paulista, em 6 de março de 1932. Graduou-se em 1957, pela Escola de Medicina e Cirurgia do Rio de Janeiro, fundada em 1912, e considerada a raiz histórica do atual curso de Medicina da Universidade Federal do Estado do Rio de Janeiro (Unirio). Realizou seu treinamento neurocirúrgico nos Estados Unidos, entre agosto de 1957 e dezembro de 1961, na Universidade de Maryland, University Hospital - Baltimore, no serviço do Prof. Dr. James G. Arnold Jr., em continuidade aos princípios estabelecidos por Harvey Cushing. Ainda neste período, tornou-se fellow na Lahey Clinic em Boston, Massachusetts, no serviço do Prof. Dr. James L. Poppen, onde teve a oportunidade de assimilar a esmerada e aprimorada técnica neurocirúrgica. ${ }^{1}$

Ingressou na Irmandade da Santa Casa de Misericórdia de São Paulo (ISCM-SP) em 1962, no serviço do pavilhão de Neurologia e Neurocirurgia, chefiado pelo Prof. Carlos Gama, onde estagiaram vários neurocirurgiões brasileiros, dentre os quais se destaca Rolando Ângelo Tenuto.

Address for correspondence DOI http://dx.doi.org/ Prof. Dr. José Carlos Esteves Veiga. 10.1055/s-0035-1556868. MD, PhD, Disciplina de Neurocirurgia ISSN 0103-5355.

da Faculdade de Ciências Médicas da Santa Casa. Rua Dr. Cesário Motta Jr. 112, São Paulo, SP, Brasil CEP: 01221020

(e-mail: neurocirurgia@santacasasp. org.br).
Em 1963, foi fundada a Faculdade de Ciências Médicas da Santa Casa de São Paulo (FCM-SC-SP), com base nos ideais do Prof. Emílio Athiê. No mesmo ano, após a morte prematura do Prof. Carlos Gama em consequência de traumatismo cranioencefálico, ${ }^{2}$ o Prof. Rui Carvalho assumiu a chefia da disciplina de Neurocirurgia. Logo foram reorganizadas e planejadas novas estratégias que culminaram com a criação, em 1966, da residência médica em Neurocirurgia, tal como a conhecemos nos dias atuais, tendo como primeiro residente o Prof. Salvador Vasconcellos de Oliveira.

Desde o início, a residência em Neurocirurgia na Santa Casa teve a duração de 4 anos (o usual à época era o término em 3 anos). O caráter inovador sempre se manteve, de modo que, em 1993, o serviço era um dos primeiros em nosso meio a oferecer conteúdo programático elaborado com duração de 5 anos.

Reconhecidamente, o Prof. Dr. Rui de Carvalho era possuidor de requintada técnica cirúrgica, considerado exímio neurocirurgião, excelente didata e dotado de elevados princípios éticos. Criou atmosfera de respeito, assiduidade, perseverança, dedicação, capacidade de trabalho e de resolução. Foi um período intenso de aprendizado e treinamento em serviço, de grande dedicação à assistência. Naquele ambiente profícuo, formaramse vários discípulos, com destaque tanto na carreira acadêmica quanto profissional, os quais ocupam hoje importante posição em vários hospitais e instituições de ensino em nosso país.

Em 1974, o Prof. Rui de Carvalho apresentou tese durante o Concurso de Livre-Docência da Disciplina de Neurocirurgia da FCM-SC-SP, constituindo-se em valiosa contribuição no estudo da mielopatia espondilótica cervical. Foi um dos principais introdutores da técnica cirúrgica de Cloward em nosso meio. Em seu trabalho, fez importantes considerações e acrescentou modificações à técnica original. Logo se tornou Professor Titular, tendo participado de inúmeras bancas examinadoras de concursos acadêmicos.

Na vida associativa, exerceu relevantes cargos na Sociedade Brasileira de Neurocirurgia, de 1980 a 1984. Foi também um dos membros fundadores da Associação dos

Copyright (c) 2015 by Thieme Publicações License terms Ltda, Rio de Janeiro, Brazil

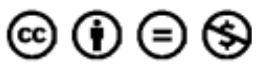


Neurocirurgiões do Estado de São Paulo (Sonesp) e membro da Harvey Cushing Society.

Introvertido e extremamente dedicado a tudo que assumia ou que dele dependia, era possuidor de caráter íntegro, pautado em princípios de elevados conceitos morais e éticos. Sua presença exercia liderança de maneira inerente e natural.

Ao longo de sua carreira profissional e acadêmica, construiu um importante legado, transmitido a seus vários discípulos. Certamente, o nome do Prof. Dr. Rui de Carvalho estará sempre atrelado à disciplina de Neurocirurgia da Faculdade de Ciências Médicas da Santa Casa de São Paulo e ao serviço de Neurocirurgia da Irmandade da Santa Casa de Misericórdia de São Paulo, por ele idealizado e iniciado. ${ }^{1}$

É com enorme sentimento de pesar que registramos o falecimento do Prof. Dr. Rui Raul Dahas de Carvalho, ocorrido em 13 de outubro de 2014, vítima da violência que impera em nossos dias, e que nos privou de um dos pioneiros da Neurocirurgia Brasileira, personagem exponencial e altamente representativo de nossa especialidade. Foi Prof. Titular, Livre
Docente da disciplina de Neurocirurgia da FCM-SC-SP e exerceu de maneira magnânima a chefia da disciplina entre 1963 e 1999. Os ensinamentos do Prof. Rui Raul continuarão a viver em nós, pois a vida bem preenchida torna-se eterna.

"Para ensinar há uma formalidade a cumprir: saber."

Eça de Queiroz

José Carlos Esteves Veiga

Raul Dahas de Carvalho Neto

Antero Costa Filho

\section{Referências}

1 Costa Filho A. A Santa Casa de Misericórdia de São Paulo e a Neurocirurgia. Arq Med Hosp Fac Cienc Med Santa Casa São Paulo. 2002;47(2):61-70

2 Carvalho RRD. In memoriam. Professor Carlos Gama. Arq Neuropsiquiatr 1963;21:293-294 